\section{$\$$ Research Square}

Preprints are preliminary reports that have not undergone peer review. They should not be considered conclusive, used to inform clinical practice, or referenced by the media as validated information.

\title{
Cerebrovascular risk factors are the predictive factor for ischemic cerebrovascular diseases in patients with Philadelphia chromosome (Ph)-negative myeloproliferative neoplasms: a case control study
}

\author{
Shirong Wen \\ the First Affiliated Hospital of Harbin Medical University \\ Wenxiao Zhang \\ Zhuhai People's Hospital (Zhuhai hospital affiliated with Jinan University) \\ Yiping Fei \\ the First Affiliated Hospital of Harbin Medical University \\ Ke Guan \\ the First Affiliated Hospital of Harbin Medical University \\ Hui Zhao \\ the First Affiliated Hospital of Harbin Medical University \\ Peng Song \\ the First Affiliated Hospital of Harbin Medical University \\ Xiangmei Ye \\ the First Affiliated Hospital of Harbin Medical University \\ Fenglin Cao \\ the First Affiliated Hospital of Harbin Medical University \\ Jin Zhou \\ the First Affiliated Hospital of Harbin Medical University \\ Yujun Pan ( $\nabla$ yujunpan@ems.hrbmu.edu.cn ) \\ the First Affiliated Hospital of Harbin Medical University https://orcid.org/0000-0002-3727-0114
}

\section{Research article}

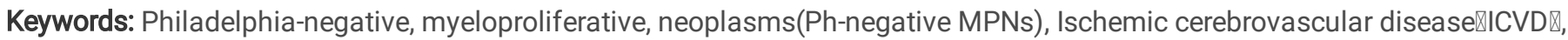
Hypertension, Smoking, Risk factors, JAK2V617F mutation, CALR mutation

Posted Date: February 10th, 2021

DOI: https://doi.org/10.21203/rs.3.rs-209712/v1

License: () (1) This work is licensed under a Creative Commons Attribution 4.0 International License. Read Full License 


\section{Abstract}

Background: The ischemic cerebrovascular disease (ICVD) is major thrombotic complication of Philadelphia chromosome (Ph)negative myeloproliferative neoplasms (Ph-negative MPNs) which included essential thrombocythemia (ET), polycythemia vera (PV) and primary myelofibrosis (PMF) leading to high disability and mortality rates. However, risk factors attributable to ICVD in Ph-negative MPNs patients are still not understood. This study aimed to identify risk factors for ICVD in Ph-negative MPNs.

Methods: Patients with Ph-negative MPNs were divided into ICVD and non-ICVD groups. The demographic, biochemical, genetic parameters (JAK2V617F and CALR mutations) were assessed. The association between these factors and ICVD was assessed using logistic regression analysis.

Results: One hundred eighty five Ph-negative MPNs patients (82 ET, 78 PV, and 25 PMF) were recruited冈and 57 (30.8\%) had ICVD which was higher than recently published data. The higher prevalence of hypertension(59.6\% vs $32.0 \%)$, smoking $(22.8 \%$ vs $6.3 \%)$,

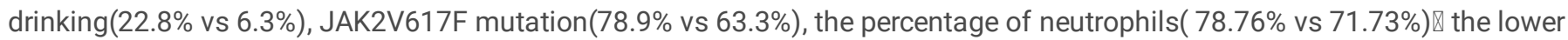
prevalence of CALR mutation( $3.2 \%$ vs $22.2 \%$ ) and the percentage of basophils $(0.82 \%$ vs $1.40 \%)$ were found in the ICVD group comparing with the non-ICVD group. The frequency of ICVD events was significantly higher in patients with JAK2V617F mutation than in those without (35.7\% and $20.3 \%, \mathrm{P}=0.034)$. Multivariate logistic regression analysis showed that hypertension $(\mathrm{OR}=2.464,95 \% \mathrm{Cl}$ 1.218-4.983, $\mathrm{p}=0.012)$ and smoking $(\mathrm{OR}=5.426,95 \% \mathrm{Cl} 1.919-15.340, \mathrm{p}=0.001)$ were significantly positively associated with ICVD events. For ET patients, both smoking $(\mathrm{OR}=4.414,95 \% \mathrm{Cl} 1.079-15.685, \mathrm{p}=0.038)$ and increased percentage of neutrophils $(\mathrm{OR}=1.080$, $95 \% \mathrm{Cl} 1.019-1.144, \mathrm{p}=0.009)$ were independently associated with ICVD incidence. Hypertension $(\mathrm{OR}=4.647,95 \% \mathrm{Cl} 1.215-17.781$, $\mathrm{p}=0.025)$, smoking $(\mathrm{OR}=6.065,95 \% \mathrm{Cl} 1.083-33.951, \mathrm{p}=0.040)$, and increased percentage of lymphocytes $(\mathrm{OR}=1.039,95 \% \mathrm{Cl} 1.002-1.078$, $\mathrm{p}=0.039$ ) were all positively correlated with ICVD risk in PV patients.

Conclusions: Our data suggest that hypertension, smoking, higher percentage of neutrophils and lymphocytes rather than JAK2V617F and CALR mutations may be associated with an elevated risk of ICVD in Ph-negative MPNs patients, although the relative role of each factor may vary in the individual subgroup. Additional studies of large patient cohorts will be essential to validate these findings.

\section{Background}

Myeloproliferative neoplasms (MPNs) are clonal disorders of hematopoietic stem cells characterized by proliferation of one or more myeloid cell lines (such as granulocytic, erythroid, megakaryocytic, and mast cells)[1,2]. According to the World Health Organization (WHO) classification(2016), MPNs include classic Philadelphia chromosome (Ph)-negative MPNs(Ph-negative MPNs) diseases which are consisted of essential thrombocythemia (ET) characterized by predominantly megakaryocyte proliferation and thrombocytosis, polycythemia vera (PV) characterized by the proliferation of all myeloid lineages, and primary myelofibrosis (PMF) in which cytokines from abnormal megakaryocytes lead to fibrosis in bone marrow and extramedullary hematopoiesis[3].

The major complication of Ph-negative MPNs was thrombosis [4,5]. Ischemic cerebrovascular diseases (ICVD) (stroke and transient ischemic attacks) are prevalent and account for approximately two-thirds of all thrombotic complications, leading to high disability and mortality rates[6]. However, the risk factors attributable to ICVD cases in Ph-negative MPNs patients are still not completely understood with several pathological processes implicated[7,8]. JAK2V617F((Janus kinase 2,JAK2) mutation (occurring within exon 14 of JAK2) is a frequent mutation in Ph-negative MPNs, and the JAK2V617F positive status is predictive of higher leukocytosis and more frequent thrombosis in patients with Ph-negative MPNs[9,10].Another mutation in the CALR gene, encoding the endoplasmic reticulumassociated calcium-binding protein calreticulin, has also been identified in Ph-negative MPNs[9,11]. Patients with ET harboring CALR mutations are at significantly lower risk of thrombosis and with PMF harboring CALR have longer overall survival [12, 13]. Some studies confirmed that baseline leukobytosis in both PV and ET patients was an independent risk factor for thrombosis [14,15]. However, Barbui's et al excluded leukocytosis as an independent predictive factor for thrombosis [16].

Noticeably, in most reports published, thrombotic events in patients with MPNs included major arterial and venous thrombotic events such as cerebrovascular accidents, cerebral venous thrombosis, transient ischemic attacks, coronary artery ischemia, peripheral arterial disease, and deep vein thrombosis. However, there is limited information on the prevalence and clinical characteristics of ICVD in Phnegative MPNs.

To better understand ICVD with Ph-negative MPNs, we examined the differences in demographic data, clinical characteristics (hematological parameters and gene mutations) of recruited Ph-negative MPNs patients and explored the risk factors for ICVD events in 
this disease.

\section{Methods}

\section{Study design and participants}

From November 2014 to February 2016, 185 patients with Ph-negative MPNs who received treatments in the First Affiliated Hospital of Harbin Medical University were enrolled in the study (age: 36-78 years). The Ph-negative MPNs were classified into ET, PV, and PMF using the diagnostic criteria published by WHO in 2016[3]. Patients were excluded from this study in case of age less than 18 years old, secondary or hereditary polycythemia, secondary or hereditary thrombocytosis, secondary myelofibrosis, or uncompleted laboratory results. The demographic data, history of hypertension, diabetes and coronary disease, habits of smoking and drinking were recorded.

Peripheral blood samples were collected from each patient at diagnosis and without any previous therapy. The plasma samples were obtained after blood centrifugation at $400 \times \mathrm{g}$ for $10 \mathrm{~min}$ at $4^{\circ} \mathrm{C}$, and stored at $-80^{\circ} \mathrm{C}$ until analysis.

Written informed consents were obtained from all patients and this study was approved by the Medical Ethics Committee of the First Affiliated Hospital of Harbin Medical University.

\section{Diagnosis of ischemic cerebrovascular disease}

ICVD was defined as neurologic dysfunctions of any severity consistent with focal brain ischemia and imaging/laboratory confirmation of an acute vascular ischemic pathology [17]. ICVD contains transient ischemic attack (TIA) and ischemic cerebral infarction. TIA classically defined as a neurological deficit duration less than 24 hours, and cerebral infarction, with irreversible damage to the brain parenchyma [18]. Ischemic cerebral infarctions are consisted of cerebral infarction, lacunar infarction and multiple cerebral infarction. These symptoms were diagnosed by neurologists and confirmed by neuroimaging examinations. Based on the diagnostic results about ICVD, the enrolled patients with Ph-negative MPNs were divided into two groups: ICVD group and non-ICVD group.

\section{Hematological analysis}

The plasma samples were obtained for hematological analysis. The hematological parameters including white blood cell count (WBC), red blood cell count (RBC), hemoglobin concentration ( $\mathrm{Hb}$ ), platelet count (PLT), hematocrit (Hct), neutrophils, percentage of neutrophils, lymphocytes, percentage of lymphocytes, percentage of monocytes, percentage of basophils, percentage of eosinophils and indirect bilirubin were determined using the automatic biochemical analyzer (Hitachi, Tokyo, Japan).

\section{Detection of JAK2V617F and CALR mutations}

The JAK2V617F and CALR mutations were detected by using an MPNs-related gene mutation detection kit (Shanghai Yuanqi BioPharmaceutical Co., Ltd., Shanghai, China) according to the manufacture's protocol. Briefly, total DNA was extracted from peripheral blood samples. Polymerase chain reaction (PCR) amplification and detection were performed under a Stratagene MX3000P real-time PCR system (Stratagene): $42^{\circ} \mathrm{C}$ for $5 \mathrm{~min}, 94^{\circ} \mathrm{C}$ for $3 \mathrm{~min}$, followed by 40 cycles at $95^{\circ} \mathrm{C}$ for $45 \mathrm{~s}$ and $60^{\circ} \mathrm{C}$ for $80 \mathrm{~s}$. All samples were measured in triplicate, and the mean $\triangle \mathrm{Ct}$ was calculated to determine mutations according to the DNA-melting curve analysis.

\section{Statistical analysis}

Data analysis was performed using SPSS (version 24.0, Chicago, IL, USA). Continuous variables were presented as mean and standard deviation (SD) or as median and interquartile range (IQR) where appropriate. The measurement data with normal distribution were assessed by Student's t-test, and non-normal data were statistically analyzed by Mann-Whitney U test. Categorical variables were presented as counts and percentages. For group differences in descriptive data, the chi-square $(\chi 2)$ test or the Fisher exact test were used. Any differences between the ICVD and non-ICVD groups in the risk of ICVD were assessed using multivariable logistic regression model. The level of significance was set at $p<0.05$.

\section{Results}

\section{Patient characteristics}


During the study period $185 \mathrm{Ph}$-negative MPNs patients were analysed. The main age of the study cohort was $55.39 \pm 12.62$ years (49.2\% female), 57 patients had ICVD (30.8\%). Demography and clinical characteristics of the cohort were presented in Talble 1. The average age of patients in ICVD group was higher than non-ICVD group $(58.24 \pm 12.34$ vs $54.12 \pm 12.44, P=0.028)$. The prevalence of hypertension, smoking, drinking, and JAK2V617F mutation were significantly higher in the ICVD group comparing with the non-ICVD group (all $P<0.05$ ). The ICVD group had lower prevalence of CALR mutation than the non-ICVD group $(P=0.017)$. Meanwhile, hematological analysis showed that the percentage of neutrophils was increased and the percentage of basophils was reduced in ICVD group (all $\mathrm{P}<0.05$ ). There were no significant differences in sex, diabetes, or blood counts (including WBC, RBC, PLT and neutrophils) between these two patient groups(all $\mathrm{P}>0.05)$.

As shown in Table 2, these 185 patients were classified as ET (82, 44.3\%), PV (78, 42.2\%) and PMF $(25,13.5 \%)$. Furthermore, these three groups of patients were divided into ICVD subgroup and non-ICVD subgroup. The incidence of ICVD in ET, PV and PMF patients was $29.3 \%, 34.6 \%$, and $24.0 \%$, respectively. The incidence of the JAK2V617F mutation in each disease was follows: $61.0 \%$ (50/82) in ET; 79.5\% (62/78) in PV; 56.0\% (14/25) in PMF. CALR mutation were detected in 15 (34.9\%), 1 (1.8\%), and 1 (33.3\%) of ET, PV and PMF patients. ET was found to be the most common subtype in Ph-negative MPNs with CALR mutation.

Older age, smoking history the percentage of neutrophils and JAK2V617F mutation were significantly higher, while the CALR mutation, the percentage of lymphocytes and basophils were lower in the ICVD subgroup in ET patients (all $P<0.05)$.

Among the PV patients, the prevalence of hypertension, smoking, drinking and the percentage of lymphocytes were recorded significantly higher in the ICVD subgroup (all $\mathrm{P}<0.05$ ). However, the percentage of basophils was decreased in the ICVD subgroup ( 0.96 vs $1.45, \mathrm{P}<0.05)$.

For the PMF patients, female sex was predominant (5/6,83.3\%) in ICVD subgroup, in contrast, male sex was predominant (14/19, $73.7 \%)$ in non-ICVD subgroup. The prevalence of hypertension and the percentage of neutrophils were increased, while the percentage of basophils was decreased in the ICVD subgroup (all $\mathrm{P}<0.05$ ).

\section{Demographic and clinical characteristics of patients with JAK2V617F or CALR mutation}

As shown in table 3, the JAK2V617F mutation was identified in 126 of the 185 patients (68.1\%). The frequency of ICVD events was significantly higher in patients with JAK2V617F mutation than in those without ( $35.7 \%$ vs $20.3 \%, P=0.034)$. Therefore, the presence of the JAK2 V617F mutation was considered a possible risk factor for ICVD.

In the JAK2V617F mutation patients, the incidence of ICVD, older age, hypertension, blood counts (WBC, RBC, Hb, Hct, neutrophils, eosinophils), the percentage of neutrophils and eosinophils increased significantly, while the percentage of lymphocytes and monocytes decreased(Table 4, all $\mathrm{P}<0.05)$.

As shown in table5, CALR mutation was detected in 103 cases and 17 were positive (PV and MPF both 1 case, ET 15 cases). In ICVD patients, CALR mutation was lower than non-ICVD patient(3.2\% vs $22.2 \% \bigotimes P=0.017 \rrbracket$ table1). The incidence of ICVD, the JAK2V617F mutation, hypertension and the percentage of neutrophils decreased significantly in CALR mutation patients $($ Table 5 , all $P<0.05)$.

\section{Identification of risk factors associated with ICVD in Ph-negative MPNs patients}

Multivariate logistic regression analysis including age, JAK2V617F mutation, CALR mutation, hypertension, smoking $₫$ percentage of neutrophils, percentage of basophils and percentage of lymphocytes were used to identify risk factors associated with ICVD incidence(Table 6). The results showed that hypertension ( $\mathrm{OR}=2.464,95 \% \mathrm{Cl} 1.218-4.983, \mathrm{P}=0.012)$ and smoking $(\mathrm{OR}=5.426,95 \% \mathrm{Cl}$ 1.919-15.340, $P=0.001$ ) were independently associated with ICVD risk in Ph-negative MPNs patients. For ET patients, both smoking ( $O R=4.414,95 \% \mathrm{Cl} 1.079-15.685, \mathrm{P}=0.038)$ and increased percentage of neutrophils $(\mathrm{OR}=1.080,95 \% \mathrm{Cl} 1.019-1.144, \mathrm{P}=0.009)$ were positively correlated with ICVD incidence. Hypertension (OR=4.647, 95\% Cl 1.215-17.781, $\mathrm{P}=0.025)$, smoking (OR=6.065, 95\% $\mathrm{Cl} 1.083-$ 33.951, $\mathrm{P}=0.040)$, and increased percentage of lymphocytes ( $\mathrm{OR}=1.039,95 \% \mathrm{Cl} 1.002-1.078, \mathrm{P}=0.039)$ were all independently associated with ICVD risk in PV patients. However, no independent risk factor of ICVD was selected for PMF patients.

\section{Discussion}

This study evaluated risk factors for ICVD among Ph-negative MPNs patients. The main finding of our study is that hypertension, smoking, increased percentage of neutrophils or lymphocytes are associated with the higher frequency of ICVD events in Ph-negative 
MPNs patients, although the relative role of each factor may vary in the individual subgroup.

As described by the 2016 WHO classification, PV, ET and PMF, which are all subcategorized as the Ph-negative MPNs [3]. ET (49.252.5\%) is regarded as the most common subtype of Ph-negative MPNs, followed by PV (27.9-34.7\%) and PMF (14.4-19.6\%) [9,16-18]. But in the Mayo Clinic cohort of 3023 patients with Ph-negative MPNs, PMF was the most common diagnosis (42\%)[19]. Our data showed the similar distribution of ET $(82,44.3 \%)$ and PV(78, 42.2\%) which difference from others. A possible explanation for this might be that regional studies have a different distribution.

In our data, the pooled prevalence of ICVD with Ph-negative MPNs patients was $30.8 \%(57 / 185)$ which was higher than recently published data. The meta-analysis of 29 cohort studies with 13,436 patients with Ph-negative MPNs showed the prevalence of cerebrovascular disease was $7.4 \%(95 \% \mathrm{Cl}, 5.0-10.8 \%)$ and transient ischemic attack was $3.5 \%(95 \% \mathrm{Cl}, 1.9-6.4 \%)$. As showed in a German study, 19.3\% (28/145) suffered from stroke [18]. A possible explanation for this might be that those published studies reported the overall thrombosis and ischemic stroke as a subtype of thrombosic events, while we focused on the ICVD with Ph-negative MPNs. On the other hand, the difference may be related to the data we accessed was from the region where has higher risk of cerebrovascular disease in the northeast China. For the same reasons, regarding the subtype analysis in our data, especially in PV and ET, the occurrence of ICVD complications was higher than previous findings $[9,18]$.

Established cerebrovascular risk factors such as hypertension, smoking, diabetes have been found to impart a consistently increased risk of vascular complications for patients with Ph-negative MPNs by some studies[16]. The prevalence of hypertension (59.6\% vs $32.0 \%)$, smoking ( $22.8 \%$ vs $6.3 \%$ ), drinking ( $22.8 \%$ vs $6.3 \%$ ), were significantly higher in the ICVD group compared with the non-ICVD group in our data, similar to the report by Zhang $Y$ et al that showed $55.5 \%$ of patients with thrombosis had at least one cerebrovascular risk factor, and at least one cerebrovascular risk factor was also a risk factor for thrombosis in Chinese PV patients[20]. Futhermore, the current results showed that hypertension and smoking were two independent risk factors for Ph-negative MPNs patients with ICVD as demonstrated by multivariate analysis. However, the other publications suggested that cerebrovascular risk factors did not encourage the development of thrombotic events in Ph-negative MPNs [15,21,22]. The difference may be due to the different subject cohorts (MPNs vs PV or ET) or number of cases. In our data, analysis of subgroups suggested the differences between the ET, PV and PMF. Smoking was independent risk factor in ET patients, on the other hand, smoking and hypertension were concomitant risk factors associated with increased risk for ICVD in PV patients. Whereas, it did not show any independent risk factor in PMF patients possibly due to the smaller number of analyzed patients.

In the last decade, growing evidence has highlighted the key role of leukocytes in the prothrombotic state and several studies have investigated the association between leukocytosis and tendency for thrombosis in patients with Ph-negative MPNs, but the conclusions were inconsistent[23]. The uncertainty was thought due to inconsistencies in the definition of leukocytosis, lack of a clear cutoff value for WBC counts, and heterogeneity in methods for its assessment[24]. Zhou et al found that neutrophil-to-lymphocyte ratio (NLR) was significantly associated with a higher risk of thrombosis in ET patients, which can predict the future thrombosis during follow-up[15].

In our data, leukocyte counts were increased in Ph-negative MPNs with ICVD, but not statistically different for patients who had ICVD or not. However, the percentage of neutrophils was significantly increased in Ph-negative MPNs patients with ICVD, as well as in ET and PMF patients. Importantly, increased percentage of neutrophils was independent risk factors for ICVD in patients with ET on multivariate analysis. The neutrophil is the most abundant leukocyte, which play central roles in the inflammatory response to the activation of blood coagulation. The activated neutrophils can produce molecules (such as reactive oxygen species, proteolytic enzymes, $\beta 2$ integrin Mac 1 or CD11b) on their cell surface to affect the hemostatic system and induce a hypercoagulable state in vivo[25]. Neutrophils from patients with Ph-negative MPNs display a number of features of enhanced activation[26]. On stimulation, normal neutrophils can expel extracellular strands of decondensed DNA in complex with histones and other neutrophil granular proteins to produce neutrophil extracellular traps (NETs)[27]. Meng et al demonstrated that NETs were found within the thrombi. In the vasculature, NETs can form a scaffolding structure onto which platelets aggregate and form thrombi[12,28]. Our study seemed to support that neutrophils were related to an increased risk of ICVD events in Ph-negative MPNs.

With the advance of molecular biology, the mutations in JAK2, MPL (trombopoietin receptor) and CALR genes are identified in PV, ET and PMF[29]. The types of driver mutations are closely related with the clinical features of Ph-negative MPNs patients[30]. These mutations are responsible for both the onset and the pathogenesis of the disease and alter importantly cellular signaling pathways. The JAK2 gene codes for the Janus kinase2 protein, which participates in the JAK-STAT signaling pathway that is important in cellular proliferation and differentiation. The proportion of patients with the mutation is variable among the studies, which is ranging from 46.7 
to $100 \%$ in patients with PV, from 31.3 to $72.1 \%$ in patients with ET, and from 25.0 to $85.7 \%$ in those with PMF. Our data showed the frequency of the patients with JAK2V617F mutation was $68.11 \%$, which was similar as the published data[31,32]. These analysis by subgroups in our cohorts showed that JAK2V617F mutation is more frequent in PV(79.5\%) than in ET(61.0\%) and PMF(56.0\%). These showed homogeneous results in the proportion of patients with the mutation have been reported by Zhang X et al in China cohorts[33]. Approximately $11.1 \%$ of analyzed 126 patients with JAK2V617F-mutated MPNs were PMF which is in accordance with recently published data from China, whereas PV was considerably lower (49.2\% vs $60.6 \%$ ) and ET was higher (39.7\% vs $30.4 \%)$ in our report. These difference may be caused by a region bias (the northeast China vs the central China) and the number of patients (126 vs 1537$)$.

As similar to the previous report by Ong et al[34], the percentage of JAK2V617F mutation was significantly higher in the ICVD subgroup than the non-ICVD subgroup(78.9\% vs $63.3 \%$ ) in our research. Meanwhile, the ICVD events were observed in $35.7 \%$ of patients with JAK2V617F mutation, compared with $20.3 \%$ of patients without JAK2V617F mutation. The frequency of thrombotic events was significantly higher in patients with JAK2V617F mutation than in those without $\$ was similar to previous observations[20]. Therefore, the presence of the JAK2V617F mutation was considered a possible risk factor for ICVD[35]. However, the current results showed that the JAK2V617F mutation was not the independent risk factors for Ph-negative MPNs patients with ICVD as demonstrated by multivariate analysis.It was thought that the higher hemoglobin and neutrophil counts, and fibrotic transformation induced by JAK2V617F take part in the pathogenesis of Ph-negative MPNs[36]. Wolach1 et al showed that JAK2V617F expression was associated with increased NETs formation in response to neutrophils stimulation in Ph-negative MPNs patients and in JAK2V617F mouse models[37]. Our results demonstrated that the older age, hypertension, blood counts (WBC, RBC, Hb, Hct, neutrophils, eosinophils), the percentage of neutrophils and eosinophils tended to be higher in patients with the JAK2V617F mutation than in those without. These suggested it was more likely due to older age, hypertension, higher percentage of neutrophils or other factors which increased the incidence of IVCD in Ph-negative MPNs patients with JAK2V617F mutation.

Our study showed the ICVD group had lower prevalence of CALR mutation than the non-ICVD group (3.2\% vs $22.2 \%$ ). The CALR gene codes for the calreticulin protein, which functions in calcium homeostasis and as a chaperone[11]. Mutations of CALR could result in the replacement of the $\mathrm{C}$-terminal negatively charged amino acids of calreticulin which offers an opportunity for immunologic targeting[38]. Calreticulin has been implicated in the survival of malignant cells and diverse biologic processes, including proliferation, apoptosis, and immunogenic cell death[39,40]. Some researches confirmed that patients with mutant CALR are with younger age, higher platelet count, lower hemoglobin, lower leukocyte count, and lower incidence of thrombosis compared to JAK2 mutated ones[12,41]. Similar to those studies, the lower leukocyte count and percentage of neutrophils were found in CALR-mutated patients as compared to without in our data.

Several limitations of our study should be acknowledged. First, patients' data were obtained from our hospital, we cannot exclude a selection bias. Second, the number of patients was also a limiting factor of this study and might affect our results.

\section{Conclusion}

ICVD remains the main complication of Ph-negative MPNs patients, multiple and concomitant factors converge to increase the ICVD risk in this disease, although the relative role of each factor may vary in the individual subgroup. Taken together, our study showed that hypertension and smoking play an important role in the prognosis of ICVD in Ph-negative MPNs patients. The percentage of neutrophils or lymphocytes as a significance of additional risk factors identified in our study will need further validation in prospective studies to determine how it may be best utilized in the management of these disorders.

\section{Declarations}

\section{- Ethics approval and consent to participate}

This study was approved by the Medical Ethics Committee of the First Affiliated Hospital of Harbin Medical University (number: 201605).

\section{- Consent for publication}

Written informed consents were obtained from all patients.

\section{- Availability of data and materials}


The datasets during the current study available from the corresponding author on reasonable request.

\section{- Competing interests}

The authors declare that they have no competing interests.

\section{- Funding}

Not applicable.

\section{- Authors' contributions}

SW interpreted the patient data and was a major contributor in writing the manuscript.

WZ analyzed the patient datas and was a contributor in writing the manuscript.

YF analyzed and interpreted the patient data regarding the Ph-negative MPNs.

KG acquired the patient data regarding the ICVD and was a contributor in writing the manuscript.

$\mathrm{HZ}$ acquired the patient data regarding the Ph-negative MPNs.

PS acquired the patient data regarding the Ph-negative MPNs.

$\mathrm{XY}$ acquired the patient data regarding the Ph-negative MPNs.

FC interpreted the patient data regarding the Ph-negative MPNs.

JZ drafted the work.

YP drafted and revised the work.

\section{- Acknowledgements}

Not applicable.

\section{Authors' information}

This section is optional.

\section{References}

1. Spivak JL. Myeloproliferative Neoplasms. N Engl J Med. 2017; 376: 2168-81.

2. Grinfeld J, Nangalia J, Baxter EJ, Wedge DC, Angelopoulos N, Cantrill R, et al. Classification and personalized prognosis in myeloproliferative neoplasms. N Engl J Med. 2018; 379: 1416-30.

3. Arber DA, Orazi A, Hasserjian R, Thiele J, Borowitz MJ, Le Beau MM, et al. The 2016 revision to the World Health Organization classification of myeloid neoplasms and acute leukemia. Blood. 2016; 127: 2391-405.

4. TefferiA, Rumi E, Finazzi G, Gisslinger $H$, Vannucchi AM, Rodeghiero F, et al. Survival and prognosis among 1545 patients with contemporary polycythemia vera: an international study. Leukemia. 2013; 27: 1874-81.

5. Duangnapasatit B, Rattarittamrong E, Rattanathammethee T, Hantrakool S, Chai-Adisaksopha C, Tantiworawit A, et al. Clinical manifestations and risk factors for complications of philadelphia chromosome-negative myeloproliferative neoplasms. Asian Pac J Cancer Prev. 2015; 16: 5013-8.

6. Srour SA, Devesa SS, Morton LM, Check DP, Curtis RE, Linet MS, et al. Incidence and patient survival of myeloproliferative neoplasms and myelodysplastic/myeloproliferative neoplasms in the United States, 2001-12. Br J Haematol. 2016; 174: 382-96.

7. Barbui T, Finazzi G, Falanga A. Myeloproliferative neoplasms and thrombosis. Blood. 2013; 122: 2176-84.

8. Andrea A, Paolo B, Ida M. Cerebral thrombosis and myeloproliferative neoplasms. Curr Neurol Neurosci Rep. 2014; 14: 496. 
9. Mónica MO, Paola AAT, Jaiberth ACA. Systematization of analytical studies of polycythemia vera, essential thrombocythemia and primary myelofibrosis, and a meta-analysis of the frequency of JAK2, CALR and MPL mutations: 2000-2018. BMC Cancer. 2019; 19: 590-604.

10. Cacemiro MDC, Cominal JG, Tognon R, Nunes NDS, Simões BP, Figueiredo-Pontes LL, et al. Philadelphia-negative myeloproliferative neoplasms as disorders marked by cytokine modulation. Hematol Transfus Cell Ther. 2018; 40(2):120-31.

11. Nangalia J, Massie CE, Baxter EJ, Nice FL, Gundem G, Wedge DC, et al. CALR mutations in myeloproliferative neoplasms with nonmutated JAK2. N Engl J Med. 2013; 369: 2391-405.

12. Rumi E, Pietra D, Ferretti V, Klampfl T, Harutyunyan AS, Milosevic JD,et al. JAK2 or CALR mutation status defines subtypes of essential thrombocythemia with substantially different clinical course and outcomes. Blood. 2014; 123: 1544-51.

13. Tefferi A, Lasho TL, Finke CM, Knudson RA, Ketterling R, Hanson CH, et al. CALR vs JAK2 vs MPL-mutated or triple-negative myelofibrosis: clinical, cytogenetic and molecular comparisons. Leukemia. 2014; 28: 1472-7.

14. Barbui T, Carobbio A, Rambaldi A, Finazzi G Perspective on thrombosis in essential thrombocythemia: is leukocytosis a causative factor? Blood. 2009; 114:759-63.

15. Zhou D, Chen W, Cheng H, Qiao JL, Zhu LL, Li ZY, et al. Clinico-hematological profile and thrombotic/hemorrhagic events in 150 Chinese patients with essential thrombocythemia. Leuk Res. 2018; 69:1-6.

16. Barbui T, Vannucchi AM, Buxhofer-Ausch V, Stefano VD, Betti S, Rambaldi A, et al. Practice-relevant revision of IPSET-thrombosis based on 1019 patients with WHO-defined essential thrombocythemia. Blood Cancer J. 2015; 27(5): e369.

17. Rungjirajittranon T, Owattanapanich W, Ungprasert P, Siritanaratkul N, Ruchutrakool T. A systematic review and meta-analysis of the prevalence of thrombosis and bleeding at diagnosis of Philadelphia-negative myeloproliferative neoplasms. BMC Cancer. 2019;19:184-92.

18. Seguro FS, Teixeira LLC, Rosa L, Silva WF, Nardinelli L, Bendit I,et al. Risk factors and incidence of thrombosis in a Brazilian cohort of patients with Philadelphia-negative myeloproliferative neoplasms. J Thromb Thrombolysis. 2020; 49(4):667-72.

19. Szuber N, Mudireddy M, Nicolosi M, Penna D, Vallapureddy RR, Lasho TL, et al. 3023 mayo clinic patients with myeloproliferative neoplasms: risk-stratified comparison of survival and outcomes data among disease subgroups. Mayo Clin Proc. 2019; 94(4):599610.

20. Zhang YH, Zhou Y, Wang YS, Teng GS, Li DP, Wang Y, et al. Thrombosis among 1537 patients with JAK2V617F-mutated myeloproliferative neoplasms: Risk factors and development of a predictive model. Cancer Med. 2020; 9(6): 2096-105.

21. Frederiksen H, Szépligeti S, Bak M, Ghanima W, Hasselbalch HC, Christiansen CF. Vascular diseases in patients with chronic myeloproliferative neoplasms - impact of comorbidity. Clin Epidemiol. 2019; 11:955-67.

22. Takata Y, Seki R, Kanajii T, Nohara M, Koteda S, Kawaguchi K, et al. Association between thromboembolic events and the JAK2 V617F mutation in myeloproliferative neoplasms. Kurume Med J. 2014; 60(3-4):89-97.

23. Marin OCP, Heller PG. Platelets as mediators of thromboinflammation in chronic myeloproliferative neoplasms. Front Immunol. $2019 ; 10: 1373-81$.

24. Carobbio A, Ferrari A, Masciulli A, Ghirardi A, Barosi G, Barbui T. Leukocytosis and thrombosis in essential thrombocythemia and polycythemia vera: a systematic review and meta-analysis. Blood Adv. 2019; 3(11):1729-37.

25. Soehnlein O, Steffens S, Hidalgo A, Weber C. Neutrophils as protagonists and targets in chronic inflammation. Nat Rev Immunol. 2017; 17:239-47.

26. Kushnir M, CohenHW, Billett Persistent neutrophilia is a marker for an increased risk of venous thrombosis. J Thromb Thrombolysis. 2016; 42:545-51.

27. Brinkmann V, Reichard U, Goosmann C, Fauler B, Uhlemann Y, Weiss DS, et al. Neutrophil extracellular traps kill bacteria. Science. 2004; 303:1532-5.

28. MengH, Yalavarthi S, Kanthi Y $₫$ Mazza LF, Elfline MA, Luke CE, et al. In vivo role of neutrophil extracellular traps in antiphospholipid antibody-Mediated venous thrombosis. Arthritis Rheumatol. 2017; 69(3):655-67.

29. Rumi E, Pietra D, Pascutto C, Guglielmelli P, Martínez-Trillos A, Casetti I, et al. Clinical effect of driver mutations of JAK2, CALR, or MPL in primary myelofibrosis. Blood. 2014; 124(7):1062-9.

30. Barzilai M, Kirgner I, Avivi I, Ellis M, Dally N, Rozovski U, et al. Characteristics and outcomes of young adults with philadelphianegative myeloproliferative neoplasms. Eur J Haematol. 2019;102(6): 504-8. 
31. Chen CC, Hsu CC, Huang CE, Chen YY, Lung J, Ho HY, et al. Enhanced risk for specific somatic myeloproliferative neoplastic mutations in patients with stroke. Curr Neurovasc Res. 2017; 14(3):222-31.

32. Shaikh MS, Shaikh MU, Adil SN, Khurshid M, Ahmed ZA. Clinico-pathological profile and outcomes of patients with polycythaemia vera, essential thrombocythaemia and idopathic myelofibrosis: a tertiary care center experience from southern Pakistan. J Ayub Med Coll Abbottabad. 2016; 28(2):293-7.

33. Zhang X, Maimaitili Y, Li Y, An L, Mao M, Fu L, et al. Detection and clinical significance of JAK2 V617F mutation in Chinese and Uyghur patients with chronic myeloproliferative in Xinjiang. Zhonghua Xue ye Xue Za Zhi. 2012; 33(12):1020-3.

34. Ong E, Barraco F, Nighoghossian N, Praire A, Desestret V, Derex L, et al. Cerebrovascular events as presenting manifestations of myeloproliferative neoplasm. Rev Neurol. 2016; 172(11):703-8.

35. Vainchenker W, Delhommeau F, Constantinescu SN, Bernard OA. New mutations and pathogenesis of myeloproliferative neoplasms. Blood. 2011;118(7):1723-35.

36. Saeidi K. Myeloproliferative neoplasms: current molecular biology and genetics. Crit rev Oncol Hematol. 2016; 98:375-89.

37. Wolach O, Sellar RS, Martinod K, Cherpokova D, McConkey M, Chappell RJ, et al. Increased neutrophil extracellular trap formation promotes thrombosis in myeloproliferative neoplasms. Sci Transl Med. 2018; 10:436-52.

38. Klampfl T, Gisslinger H, Harutyunyan AS, Nivarthi H, Rumi E, Milosevic JD, et al. Somatic Mutations of Calreticulin in Myeloproliferative Neoplasms. N Engl J Med. 2013; 369: 2379-90.

39. Vannucchi AM, Guglielmelli P. JAK2 mutation-related disease and thrombosis. Semin Thromb Hemost. 2013; 39: 496-506.

40. Luo B, Lee AS. The critical roles of endoplasmic reticulum chaperones and unfolded protein response in tumorigenesis and anticancer therapies. Oncogene. 2013; 32: 805-18.

41. Zhou A, Afzal A, Oh ST. Prognostication in philadelphia chromosome negative myeloproliferative neoplasms: a review of the recent literature. Curr Hematol Malig Rep 2017; 12(5): 397-405.

\section{Tables}

Table 1. Demographic and clinical characteristics of the cohort according to the presence of ICVD 


\begin{tabular}{|c|c|c|c|}
\hline Characteristics & $\begin{array}{l}\text { ICVD group } \\
(\mathrm{N}=57)\end{array}$ & $\begin{array}{l}\text { Non-ICVD group } \\
(\mathrm{N}=128)\end{array}$ & $\mathrm{p}$ value \\
\hline \multicolumn{4}{|l|}{ Demographic characteristics } \\
\hline Gender, female/male, $n$ & $29 / 28$ & $62 / 67$ & 0.806 \\
\hline Age, years mean (SD) & $58.24(12.34)$ & $54.12(12.44)$ & $0.028^{*}$ \\
\hline \multicolumn{4}{|l|}{ Vacular risk factors, $\mathrm{n}(\%)$} \\
\hline Hypertension & $34(59.6)$ & $41(32.0)$ & $0.000 *$ \\
\hline Diabetes mellitus & $7(12.3)$ & $14(10.9)$ & 0.790 \\
\hline Coronary artery disease & $12(21.1)$ & $25(19.5)$ & 0.611 \\
\hline Smoking & $13(22.8)$ & $8(6.3)$ & $0.001^{*}$ \\
\hline Drinking & $13(22.8)$ & $8(6.3)$ & $0.001^{*}$ \\
\hline \multicolumn{4}{|c|}{ Hematological parameters, median(IQR) } \\
\hline WBC $\left(\times 10^{9} / \mathrm{L}\right)$ & $12.26(6.65-17.68)$ & $11.51(8.31-15.57)$ & 0.380 \\
\hline $\operatorname{RBC}\left(\times 10^{9} / \mathrm{L}\right)$ & $5.80(2.57-7.11)$ & $5.12(2.02-7.92)$ & 0.287 \\
\hline $\mathrm{Hb}(\mathrm{g} / \mathrm{L})$ & $165.81(120.00-213.62)$ & $158.55(107.49-215.52)$ & 0.364 \\
\hline $\operatorname{PLT}\left(\times 10^{9 / L}\right)$ & $445.40(249.10-814.50)$ & $507.30(269.95-921.23)$ & 0.524 \\
\hline Hct (\%) & $49.59(35.42-65.33)$ & $46.69(31.22-52.68)$ & 0.243 \\
\hline NEUT\% (\%) & 78.76(70.08-84.73) & 71.73 (64.84-81.14) & $0.017^{*}$ \\
\hline NEUT\# $\left(\times 10^{9} / \mathrm{L}\right)$ & $9.68(5.79-14.72)$ & $7.93(5.17-12.23)$ & 0.196 \\
\hline LYMPH\% (\%) & 14.34(8.84-23.30) & $17.73(10.68-25.53)$ & 0.237 \\
\hline LYMPH\# $\left(\times 10^{9 / L}\right)$ & $1.66(1.38-2.13)$ & $1.81(1.36-2.50)$ & 0.493 \\
\hline MONO\% (\%) & $4.12(3.06-5.57)$ & $4.83(3.30-6.93)$ & 0.056 \\
\hline BASO \% (\%) & $0.82(0.40-1.54)$ & $1.40(0.73,2.15)$ & $0.003^{*}$ \\
\hline $\mathrm{EO} \% \varangle \% \square \square$ & $2.02(1.24-3.24)$ & $1.78(1.03-3.20)$ & 0.975 \\
\hline Indirect bilirubin $(\mu \mathrm{mol} / \mathrm{L})$ & $11.90(9.48-18.32)$ & $12.30(9.50-16.20)$ & 0.574 \\
\hline JAK2V617F mutation, $\mathrm{n}(\%)$ & $45(78.9)$ & $81(63.3)$ & $0.035^{\star}$ \\
\hline CALR mutation, $\%$ & $3.2(1 / 31)$ & $22.2(16 / 72)$ & $0.017^{*}$ \\
\hline
\end{tabular}

Abbreviation: $S D$ standard deviation, $I Q R$ interquartile range, $W B C$ white blood cell count, $R B C$ red blood cell count, $H b$ hemoglobin concentration, PLT platelet count, Hct hematocrit, NEUT\% Percentage of neutrophils, NEUT\# Neutrophils, LYMPH\% Percentage of lymphocytes, LYMPH\# Lymphocytes, MONO\% Percentage of monocytes, BASO\% Percentage of basophils, EO\% Percentage of eosinophils

$*, p<0.05$ compared with the non-ICVD group

Table 2. Comparison of demographic and clinical characteristics between ICVD subgroup and non-ICVD subgroup among patients with essential thrombocythemia (ET), polycythemia vera (PV) or primary myelofibrosis (PMF) 


\begin{tabular}{|c|c|c|c|c|c|c|}
\hline \multirow[t]{2}{*}{ Characteristics } & \multicolumn{2}{|c|}{ ET patients,n=82 } & \multicolumn{2}{|c|}{ PV patients, $n=78$} & \multicolumn{2}{|c|}{ PMF patients,n=25 } \\
\hline & $\begin{array}{l}\text { ICVD } \\
\text { subgroup }\end{array}$ & $\begin{array}{l}\text { Non-ICVD } \\
\text { subgroup }\end{array}$ & $\begin{array}{l}\text { ICVD } \\
\text { subgroup }\end{array}$ & $\begin{array}{l}\text { Non-ICVD } \\
\text { subgroup }\end{array}$ & ICVD subgroup & $\begin{array}{l}\text { Non-ICVD } \\
\text { subgroup }\end{array}$ \\
\hline Case,n(\%) & $24(29.3 \%)$ & $58(70.7 \%)$ & $27(34.6 \%)$ & $51(65.4 \%)$ & $6(24.0 \%)$ & $19(76.0 \%)$ \\
\hline $\begin{array}{l}\text { Gender, female/male, } \\
\mathrm{n}\end{array}$ & $13 / 11$ & $32 / 26$ & $10 / 17$ & $24 / 27$ & $5 / 1^{\star}$ & $5 / 14$ \\
\hline $\begin{array}{l}\text { Age, years mean } \\
\text { (SD) }\end{array}$ & $\begin{array}{l}60.21( \\
13.15)^{\star}\end{array}$ & $52.33(13.62)$ & $56.34(12.19)$ & $55.24(12.77)$ & $63.52(12.17)$ & $59.82(15.36)$ \\
\hline \multicolumn{7}{|l|}{$\begin{array}{l}\text { Vacular risk factors, } \\
\mathrm{n}(\%)\end{array}$} \\
\hline Hypertension & $9(37.50)$ & $12(20.70)$ & $21(77.8)^{*}$ & $27(52.8)$ & $4(66.7)$ & $2(10.5)$ \\
\hline Diabetes mellitus & $4(16.7)$ & $4(6.9)$ & $2(7.4)$ & $8(15.7)$ & $1(16.7)$ & $2(10.5)$ \\
\hline $\begin{array}{l}\text { Coronary artery } \\
\text { disease }\end{array}$ & $6(25.0)$ & $15(25.9)$ & $6(22.2)$ & $10(19.6)$ & $1(16.7)$ & $0(0.0)$ \\
\hline Smoking & $7(29.2) *$ & $6(10.3)$ & $6(22.2) *$ & $2(3.9)$ & 0 & 0 \\
\hline Drinking & $6(25.0)$ & $6(10.3)$ & $7(25.9) \star$ & $2(3.9)$ & 0 & 0 \\
\hline \multicolumn{7}{|l|}{$\begin{array}{l}\text { Hematological } \\
\text { parameters, } \\
\text { median(IQR) }\end{array}$} \\
\hline WBC $\left(\times 10^{9} / \mathrm{L}\right)$ & $\begin{array}{l}12.30(8.79- \\
17.78)\end{array}$ & $\begin{array}{l}11.50(8.96- \\
14.91)\end{array}$ & $\begin{array}{l}12.56(9.48- \\
16.81)\end{array}$ & $\begin{array}{l}12.26(9.21- \\
17.42)\end{array}$ & $\begin{array}{l}17.50(8.99- \\
21.61)\end{array}$ & $\begin{array}{l}6.29(4.04- \\
17.00)\end{array}$ \\
\hline $\operatorname{RBC}\left(\times 10^{9} / \mathrm{L}\right)$ & $\begin{array}{l}4.75(4.53- \\
6.38)\end{array}$ & $\begin{array}{l}4.65(4.42- \\
5.23)\end{array}$ & $\begin{array}{l}7.45(6.12- \\
7.11)\end{array}$ & $\begin{array}{l}7.38(5.93- \\
7.92)\end{array}$ & $\begin{array}{l}4.13(2.57- \\
5.81)\end{array}$ & $\begin{array}{l}3.26(2.02- \\
4.85)\end{array}$ \\
\hline $\mathrm{Hb}(\mathrm{g} / \mathrm{L})$ & $\begin{array}{l}143.50 \\
(118.90- \\
160.08)\end{array}$ & $\begin{array}{l}141.50 \\
(120.98- \\
159.73)\end{array}$ & $\begin{array}{l}205.30 \\
(180.15- \\
228.11)\end{array}$ & $\begin{array}{l}205.92(178.32- \\
234.36)\end{array}$ & $\begin{array}{l}114.68 \text { (72.53- } \\
165.32)\end{array}$ & $\begin{array}{l}94.48(50.22- \\
145.45)\end{array}$ \\
\hline $\operatorname{PLT}\left(\times 10^{9} / \mathrm{L}\right)$ & $\begin{array}{l}826.30 \\
(645.58- \\
1057.30)\end{array}$ & $\begin{array}{l}932.20(768.45- \\
1092.50)\end{array}$ & $\begin{array}{l}359.7(192.78- \\
487.4)\end{array}$ & $\begin{array}{l}338.40(197.25- \\
432.95)\end{array}$ & $\begin{array}{l}215.14(178.33- \\
330.72)\end{array}$ & $\begin{array}{l}\text { 207.01(133.56- } \\
356.03)\end{array}$ \\
\hline Hct (\%) & $\begin{array}{l}43.68(34.76- \\
46.85)\end{array}$ & $\begin{array}{l}40.12(36.06- \\
44.60)\end{array}$ & $\begin{array}{l}\text { 79.54(71.86- } \\
84.99)\end{array}$ & $\begin{array}{l}80.35(70.00- \\
85.46)\end{array}$ & $\begin{array}{l}36.14(20.13- \\
53.21)\end{array}$ & $\begin{array}{l}27.87(17.52- \\
40.22)\end{array}$ \\
\hline NEUT\% (\%) & $\begin{array}{l}76.48(66.12- \\
76.48)^{\star}\end{array}$ & $\begin{array}{l}70.24(61.16- \\
79.35)\end{array}$ & $\begin{array}{l}61.21(54.61- \\
68.70)\end{array}$ & $\begin{array}{l}60.31(57.00- \\
64.91)\end{array}$ & $\begin{array}{l}80.67(65.80- \\
86.01)^{\star}\end{array}$ & $\begin{array}{l}65.53(58.30- \\
71.17)\end{array}$ \\
\hline NEUT\# $\left(\times 10^{9} / \mathrm{L}\right)$ & $\begin{array}{l}9.68(5.92- \\
14.72)\end{array}$ & $\begin{array}{l}7.40(5.80- \\
11.27)\end{array}$ & $\begin{array}{l}10.45(7.81- \\
14.21)\end{array}$ & $\begin{array}{l}9.97(6.11- \\
14.29)\end{array}$ & $\begin{array}{l}14.85(6.28- \\
17.97)^{\star}\end{array}$ & $\begin{array}{l}3.69(1.91- \\
6.60)\end{array}$ \\
\hline LYMPH\% (\%) & $\begin{array}{l}15.70(7.53- \\
23.52)^{\star}\end{array}$ & $\begin{array}{l}20.30(12.82- \\
28.15)\end{array}$ & $\begin{array}{l}13.64(9.93- \\
25.15)^{\star}\end{array}$ & $\begin{array}{l}10.80(7.13- \\
18.88)\end{array}$ & $\begin{array}{l}16.31(7.18- \\
38.00)\end{array}$ & $\begin{array}{l}24.42(7.00- \\
59.57)\end{array}$ \\
\hline LYMPH\# (× $\left.10^{9} / \mathrm{L}\right)$ & $\begin{array}{l}1.84(1.53- \\
2.13)\end{array}$ & $\begin{array}{l}2.25(1.64- \\
2.76)\end{array}$ & $\begin{array}{l}1.60(1.32- \\
1.99)\end{array}$ & $\begin{array}{l}1.56(1.30- \\
1.91)\end{array}$ & $\begin{array}{l}1.82(1.16- \\
2.98)\end{array}$ & $\begin{array}{l}1.96(0.23- \\
9.25)\end{array}$ \\
\hline MONO\% (\%) & $\begin{array}{l}4.48(2.19- \\
8.15)\end{array}$ & $\begin{array}{l}4.59(1.00- \\
9.82)\end{array}$ & $\begin{array}{l}3.41(0.40- \\
6.54)\end{array}$ & $\begin{array}{l}3.86(0.94- \\
8.05)\end{array}$ & $\begin{array}{l}6.29(1.54- \\
18.79)\end{array}$ & $\begin{array}{l}9.09(2.00- \\
22.54)\end{array}$ \\
\hline BASO \% (\%) & $\begin{array}{l}0.67(0.36- \\
1.37)^{\star}\end{array}$ & $\begin{array}{l}1.04(0.59- \\
1.79)\end{array}$ & $\begin{array}{l}0.96(0.40- \\
1.44)^{\star}\end{array}$ & $\begin{array}{l}1.45(0.74- \\
1.91)\end{array}$ & $\begin{array}{l}1.80(0.24- \\
2.94)\end{array}$ & $\begin{array}{l}3.46(0.14- \\
10.22)\end{array}$ \\
\hline EO\%区\%ष囚 & $\begin{array}{l}2.1(1.54- \\
3.65)\end{array}$ & $\begin{array}{l}2.26(1.17- \\
3.23)\end{array}$ & $2.2(1.27-3.17)$ & $\begin{array}{l}1.79(0.96- \\
3.28)\end{array}$ & $1.04(0,54-1.19)$ & $\begin{array}{l}1.26(0.50- \\
2.03)\end{array}$ \\
\hline $\begin{array}{l}\text { Indirect bilirubin } \\
(\mu \mathrm{mol} / \mathrm{L})\end{array}$ & $9.5(8.1-12.3)$ & $10.2(7.9-12.4)$ & $\begin{array}{l}20.9(14.3- \\
24.70\end{array}$ & $\begin{array}{l}16.1(11.1- \\
21.1)\end{array}$ & $\begin{array}{l}11.1(10.4- \\
15.9)\end{array}$ & $\begin{array}{l}14.7(12.6- \\
16.0)\end{array}$ \\
\hline $\begin{array}{l}\text { JAK2V617F mutation, } \\
\mathrm{n}(\%)\end{array}$ & $19(79.2)^{\star}$ & $31(53.4)$ & $21(77.8)$ & $41(80.4)$ & $5(83.3)$ & $9(47.4)$ \\
\hline
\end{tabular}


Abbreviation: $S D$ standard deviation, $I Q R$ interquartile range, $W B C$ white blood cell count, $R B C$ red blood cell count, $H b$ hemoglobin concentration, PLT platelet count, Hct hematocrit, NEUT\% Percentage of neutrophils, NEUT\# Neutrophils, LYMPH\% Percentage of lymphocytes, LYMPH\# Lymphocytes, MONO\% Percentage of monocytes, BASO\% Percentage of basophils, EO\% Percentage of eosinophils

$*, p<0.05$ compared with the non-ICVD subgroup

Table 3 Analysis of the JAK2V617F mutation

\begin{tabular}{|c|c|c|c|c|c|c|c|c|c|}
\hline \multirow[t]{2}{*}{ Characteristics } & \multicolumn{2}{|l|}{ Total $n=185$} & \multirow{2}{*}{$\begin{array}{l}P \\
\text { value } \\
x^{2-} \\
\text { test }\end{array}$} & \multicolumn{2}{|l|}{ ET $n=82$} & \multicolumn{2}{|l|}{$P V n=78$} & \multicolumn{2}{|l|}{ PMF n=25 } \\
\hline & JAK2V617F & $\begin{array}{l}\text { Wild } \\
\text { type }\end{array}$ & & JAK2V617F & $\begin{array}{l}\text { Wild } \\
\text { type }\end{array}$ & JAK2V617F & $\begin{array}{l}\text { Wild } \\
\text { type }\end{array}$ & JAK2V617F & $\begin{array}{l}\text { Wild } \\
\text { type }\end{array}$ \\
\hline Case,n & 126 & 59 & 0.034 & 50 & 32 & 62 & 16 & 14 & 11 \\
\hline ICVD, n(\%) & $45(35.7)$ & $12(20.3)$ & & 19(38.0) & $5(15.6)$ & 21(33.9) & $6(37.5)$ & $5(35.7)$ & $1(9.1)$ \\
\hline $\begin{array}{l}\text { Non-ICVD, } \\
\mathrm{n}(\%)\end{array}$ & $81(64.3)$ & 47(79.7) & & $31(62.0)$ & $27(84.4)$ & $41(66.1)$ & $\begin{array}{l}10( \\
62.5)\end{array}$ & $9(64.3)$ & 10(90.9) \\
\hline
\end{tabular}

Table 4 Demographic and clinical characteristics in patients with or without JAK2V617(+) 


\begin{tabular}{|c|c|c|c|}
\hline Characteristics & $\begin{array}{l}\text { JAK2V617F } \\
(n=126)\end{array}$ & $\begin{array}{l}\text { Wild type } \\
(n=59)\end{array}$ & p value \\
\hline ICVD, n(\%) & $45(35.7)$ & $12(20.3)$ & $0.034^{\star}$ \\
\hline Gender, female/male, $\mathrm{n}$ & $57 / 69$ & $32 / 27$ & 0.254 \\
\hline Age, years mean (SD) & $57.41(11.94)$ & $50.44(11.44)$ & $0.000^{*}$ \\
\hline \multicolumn{4}{|c|}{ Hematological parameters, median(IQR) } \\
\hline $\mathrm{WBC}\left(\times 10^{9} / \mathrm{L}\right)$ & $14.31(10.27-17.91)$ & $8.28(5.94-10.54)$ & $0.000^{*}$ \\
\hline $\operatorname{RBC}\left(\times 10^{9} / \mathrm{L}\right)$ & $6.00(4.83-7.61)$ & $4.58(3.77-5.71)$ & \multirow{2}{*}{$0.000^{*}$} \\
\hline $\mathrm{Hb}(\mathrm{g} / \mathrm{L})$ & $176.10(141.75-210.53)$ & $132.40(101.00-177.10)$ & \\
\hline $\operatorname{PLT}\left(\times 10^{9} / \mathrm{L}\right)$ & $507.30(309.50-689.40)$ & $381(184.00-833.90)$ & \multirow{2}{*}{0.098} \\
\hline Hct(\%) & 51.34(32.64-66.85) & $39.21(24.13-53.38)$ & \\
\hline MCV(fl) & 86.91(80.06-91.33) & 86.89(81.93-92.38) & $0.000^{\wedge}$ \\
\hline $\mathrm{MCH}(\mathrm{pg})$ & 28.97(26.35-31.40) & $29.50(27.23-31.66)$ & 0.490 \\
\hline $\mathrm{MCHC}(\mathrm{g} / \mathrm{L})$ & $331.70(320.00-347.05)$ & $332.50(312.58-359.60)$ & 0.475 \\
\hline NEUT\%(\%) & 78.75(70.42-84.52) & 66.74(59.93-71.73) & 0.750 \\
\hline NFUT\# $\left(\times 10^{9} / 1\right)$ & 10.52(7.36-14.08) & $5.37(3.90-7.15)$ & $0.000^{*}$ \\
\hline & 14.23(8.53-18.78) & 25.05(17.50-29.35) & $0.000^{*}$ \\
\hline LYIVIPH\%(\%) & $1.72(1.37-2.34)$ & $1.85(1.33-2.48)$ & $0.000^{*}$ \\
\hline LYMPH\# $\left(\times 10^{9} / \mathrm{L}\right)$ & $3.98(2.80-5.62)$ & $5.75(4.74-7.37)$ & \multirow[t]{2}{*}{0.968} \\
\hline MONO\%(\%) & $0.51(0.38-0.75)$ & $0.46(0.35-0.67)$ & \\
\hline MONO\#(×109/L) & $1.33(0.64-2.10)$ & $0.90(0.38-1.74)$ & \multirow{2}{*}{0.070} \\
\hline BASO\%(\%) & $1.93(1.22-3.22)$ & $1.50(0.56-2.47)$ & \\
\hline $\begin{array}{l}\text { EO\%(\%) } \\
\text { EO\#(×10\%/L) }\end{array}$ & $0.27(0.16-0.50)$ & $0.13(0.04-0.24)$ & $0.009^{*}$ \\
\hline & & & $0.000^{\star}$ \\
\hline
\end{tabular}

Abbreviation: $S D$ standard deviation, $I Q R$ interquartile range, $W B C$ white blood cell count, $R B C$ red blood cell count, $H b$ hemoglobin concentration, PLT platelet count, Hct hematocrit, MCV:Erythrocyte mean corpuscular volume; $\mathrm{MCH}$ :mean hemoglobin concentration; MCHC: mean corpuscular hemoglobin concentration NEUT\% Percentage of neutrophils, NEUT\# Neutrophils, $L Y M P H \%$ Percentage of lymphocytes, LYMPH\# Lymphocytes, MONO\% Percentage of monocytes, MONO\#:Monocytes; BASO\% Percentage of basophils, EO\% Percentage of eosinophilsEO\#:Eosinophils

*, $p<0.05$ JAK2V617(+) compared with wild type

Table 5 Demographic and clinical characteristics of patients with or without CALR(+) 


\begin{tabular}{|c|c|c|c|}
\hline Characteristics & $\begin{array}{l}\text { CALR(+) } \\
(n=17)\end{array}$ & $\begin{array}{l}\text { Wild type } \\
(n=86)\end{array}$ & $\mathrm{p}$ value \\
\hline ICVD, n(\%) & $1(5.9)$ & $30(34.9)$ & $0.017^{*}$ \\
\hline JAK2V617F,n(\%) & $0(0.0)$ & $75(87.2)$ & $0.000^{*}$ \\
\hline Age, years mean (SD) & 48.47(13.52) & $57.50(11.85)$ & $0.006^{*}$ \\
\hline Gender, female/male, $n$ & $12 / 5$ & $42 / 44$ & 0.101 \\
\hline \multicolumn{4}{|c|}{ Hematological parameters, median(IQR) } \\
\hline $\mathrm{WBC}\left(\times 10^{9} / \mathrm{L}\right)$ & $9.40(7.24-11.76)$ & $12.88(9.13-16.51)$ & $0.003^{*}$ \\
\hline $\mathrm{RBC}\left(\times 10^{9} / \mathrm{L}\right)$ & $4.26(3.15-5.75)$ & $6.46(5.33-8.75)$ & $0.000^{*}$ \\
\hline $\mathrm{Hb}(\mathrm{g} / \mathrm{L})$ & $132.40(110.00-142.85)$ & 6.55(5.10-7.86) & $0.000^{*}$ \\
\hline $\operatorname{PLT}\left(\times 10^{9} / \mathrm{L}\right)$ & $828.20(464.10-1000.05)$ & $454.00(273.25-829.80)$ & $0.047^{\star}$ \\
\hline $\operatorname{Hct}(\%)$ & 84.68(81.53-91.62) & $87.41(81.37-90.24)$ & $0.000^{\star}$ \\
\hline MCV(fl) & $30.07(28.72-31.16)$ & 29.02(26.71-31.71) & 0.432 \\
\hline $\mathrm{MCH}(\mathrm{pg})$ & $344.50(315.25-363.35)$ & $333.50(321.20-352.58)$ & 0.764 \\
\hline NEUT\%(\%) & $64.45(58.16-70.08)$ & $79.55(69.20-84.99)$ & 0.554 \\
\hline & $5.57(4.50-7.49)$ & $10.09(6.88-13.55)$ & $0.001^{*}$ \\
\hline NEUI \# $\left(\times 10^{3} / \mathrm{L}\right)$ & $27.09(22.32-30.45)$ & $13.50(8.36-20.48)$ & $0.001^{*}$ \\
\hline LYMPH\%(\%) & $2.15(1.67-2.67)$ & $1.57(1.31-2.11)$ & $0.000^{*}$ \\
\hline LYMPH\# $\left(\times 10^{9} / \mathrm{L}\right)$ & $5.62(4.85-7.61)$ & $3.81(2.70-5.28)$ & $0.032^{*}$ \\
\hline MONO\%(\%) & $0.58(0.42-0.81)$ & $0.47(0.36-0.59)$ & \\
\hline MONO\#(×109/L) & $0.95(0.75-1.04)$ & $1.30(0.65-1.86)$ & 0.001 \\
\hline BASO $\%(\%)$ & $1.26(0.60-2.01)$ & $1.94(1.22-3.27)$ & $0.1 \angle 4$ \\
\hline EO\%(\%) & $0.11(0.05-0.22)$ & $0.26(0.14-0.48)$ & $0 . \angle 20$ \\
\hline $\mathrm{EO \#}\left(\times 10^{9} / \mathrm{L}\right)$ & & & $0.038^{*}$ \\
\hline Vacular risk factors, n(\%) & $1(17.6)$ & $43(50.5)$ & $0.002^{*}$ \\
\hline Hypertension & $8(47.1)$ & $61(70.9)$ & \\
\hline Diabetes mellitus & $4(23.5)$ & $24(27.9)$ & $0.014^{*}$ \\
\hline Coronary artery disease & $2(11.8)$ & 10(11.6) & 0.056 \\
\hline \multirow[t]{2}{*}{ Smoking/Drinking } & & & 0.711 \\
\hline & & & 0.987 \\
\hline
\end{tabular}

Abbreviation: $S D$ standard deviation, $I Q R$ interquartile range, $W B C$ white blood cell count, $R B C$ red blood cell count, $H b$ hemoglobin concentration, $P L T$ platelet count, Hct hematocrit, MCV:Erythrocyte mean corpuscular volume; $\mathrm{MCH}$ :mean hemoglobin concentration; MCHC: mean corpuscular hemoglobin concentration NEUT\% Percentage of neutrophils, NEUT\# Neutrophils, LYMPH\% Percentage of lymphocytes, LYMPH\# Lymphocytes, MONO\% Percentage of monocytes, MONO\#:Monocytes; BASO\% Percentage of basophils, EO\% Percentage of eosinophilsEO\#:Eosinophils

*, $p<0.05 \operatorname{CALR}(+)$ compared with wild type 
Table 6. Associations between risk factors and the presence of ICVD in Ph-negative MPNs patients

\begin{tabular}{|lllll|}
\hline Patients & Factors & OR & $95 \% \mathrm{Cl}$ & p value \\
\hline Ph-negative MPNs & Hypertension & 2.464 & $1.218 \sim 4.983$ & 0.012 \\
\cline { 2 - 5 } & Smoking & 5.426 & $1.919 \sim 15.340$ & 0.001 \\
\hline ET & Smoking & 4.114 & $1.079 \sim 15.685$ & 0.038 \\
\cline { 2 - 5 } & NEUT\% & 1.08 & $1.019 \sim 1.144$ & 0.009 \\
\hline PV & Hypertension & 4.647 & $1.215 \sim 17.781$ & 0.025 \\
\cline { 2 - 5 } & Smoking & 6.065 & $1.083 \sim 33.951$ & 0.040 \\
\cline { 2 - 5 } & LYMPH\% & 1.039 & $1.002 ~ 1.078$ & 0.039 \\
\hline
\end{tabular}

OR: odds ratio; Cl: confidence interval 